References

1. Budenz DL, Chen PP, Weaver YK. Conjunctival advancement for late-onset filtering bleb leaks: indications and outcomes. Arch Ophthalmol 1999;117:14-9.

2. Mardelli PG, Lederer CM Jr, Murray PL, Pastor SA, Hassanein KM. Slit-lamp needle revision of failed filtering blebs using mitomycin C. Ophthalmology 1996;103:1946-55.

3. Greenfield DS, Liebmann JM, Jee J, Ritch R. Late-onset bleb leaks after glaucoma filtering surgery. Arch Ophthalmol 1998;116:443-7.

4. Chen PP, Palmberg PF. Needling revision of glaucoma drainage device filtering blebs. Ophthalmology 1997;104:1004-10.

5. Kosmin AS, Wishart PK. A full-thickness scleral graft for the surgical management of a late filtration bleb leak. Ophthalmic Surg Lasers 1997;28:461-8.

6. Ellis DG, Cheng Q, Lee DA. The effects of growth factors on Tenon's capsule fibroblasts in serum-free culture. Curr Eye Res 1996;15:27-35.

7. Gammon RR, Prum BE Jr, Avery N, Mintz PD. Rapid preparation of small-volume autologous fibrinogen concentrate and its same day use in bleb leaks after glaucoma filtration surgery. Ophthalmic Surg Lasers 1998;29:1010-2.

8. Doyle JW, Smith MF, Garcia JA, Schultz G, Sherwood MB Treatment of bleb leaks with transforming growth factor-beta in the rabbit model. Invest Ophthalmol Vis Sci 1997;38:1630-4.

Hidetaka Maeda

Ayako Eno

Makoto Nakamura

Akira Negi

Department of Ophthalmology

Kobe University

Kobe, Japan

Hidetaka Madea, MD

Department of Ophthalmology

Kobe University School of Medicine

7-5-2 Kusunoki-cho

Chuo-ku, Kobe-shi

Hyougo-ken 650, Japan

Tel: +81783826048

Fax: +81783826059

e-mail: hidetaka@med.kobe-u.ac.jp

Sir,

\section{Early blindness due to retinopathy of infantile cystinosis}

Cystinosis is a rare autosomal recessive condition with a defect in lysosomal transport of cystine. ${ }^{1}$ This results in accumulation of cystine in the kidneys and other organs and tissues including the eyes. ${ }^{2}$ This disease is most common in French Canadians, with reported prevalence of 1 in $326000 .{ }^{3}$ Cystinosis can present in infantile, juvenile and adult (non-nephropathic, benign) forms. The infantile form is characterised by Fanconi's syndrome with growth retardation, rickets and progressive renal failure leading to renal transplant by the age of 10-13 years. Depigmentation of skin and hair occurs but intellect is normal. The ocular presentation of cystinosis includes (1) photophobia and blepharospasm due to crystalline keratopathy, (2) reduced vision due to corneal or retinal and retinal pigment epithelium deposits and (3) open angle glaucoma from deposits in the meshwork as well as angle closure due to iris thickening from cystalline deposits. ${ }^{4}$ We describe a case of infantile cystinosis which has resulted in progressive blindness from retinal deposition of cystine at an earlier than expected age.

\section{Case report}

A 5-year-old Asian boy with infantile cystinosis was referred to the regional paediatric team due to progressive visual failure. At about 2 years of age his visual acuity by Kay pictures was $6 / 12$. Over the following 2-3 years his vision deteriorated to $1 / 60$ in the right and 3/60 in the left eye. Initially his visual failure was attributed to the crystalline keratopathy.

Examination showed sluggish pupil reactions but no relative afferent pupil defect. There was no significant refractive error. Slit-lamp examination showed a mild crystalline keratopathy involving the anterior stroma. Fundoscopy revealed small crystalline-like deposits scattered throughout the retinal layer in both eyes (Fig. 1). The electroretinogram showed reduced scotopic and photopic (pattern) amplitudes. The visual evoked potentials showed a delay in the P100 component.

\section{Comment}

Cystine crystals may be deposited in the cornea, conjunctiva, lens, sclera, ciliary body, iris, trabecular meshwork, choroid, retinal pigment epithelium and retina. ${ }^{5-7}$ In the cornea, cystinosis begins in the anterior peripheral cornea and progresses more centrally and into deeper stroma. ${ }^{5}$ Deposition of crystals is usually in the corneal stroma but epithelial and endothelial deposits have been reported. ${ }^{6-8}$ Corneal cystine crystals can be seen as early as 1 year of age. ${ }^{8}$ The keratopathy caused by cystinosis may be treated with cysteamine (mercaptamine) or penetrating keratoplasty. ${ }^{9-11}$ Retinal

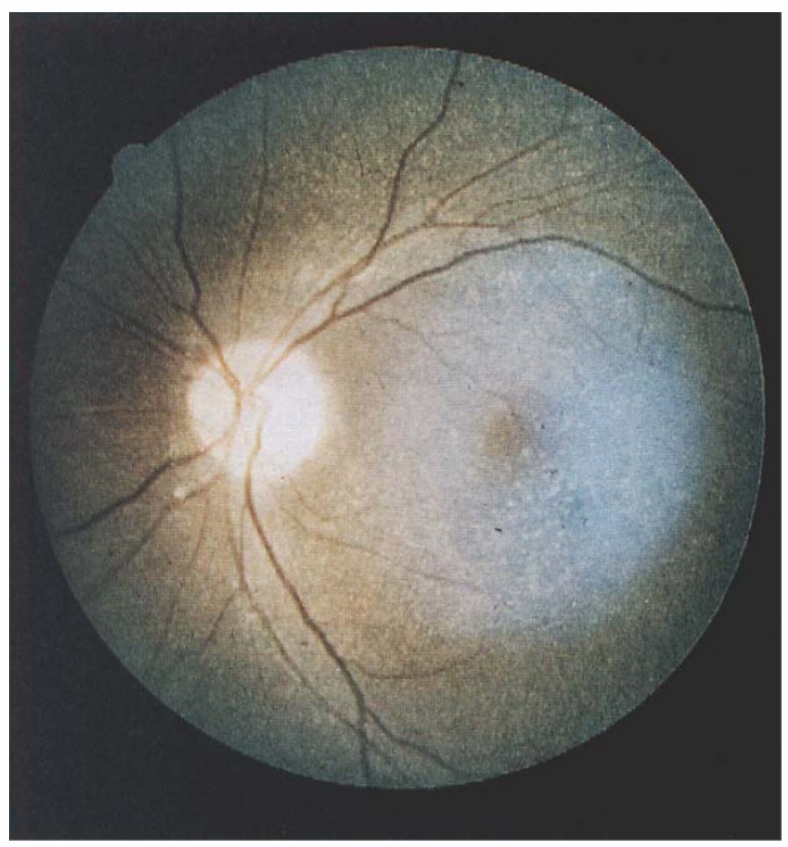

Fig. 1. Fundus photograph showing the retinopathy caused by cystinosis. 
pigment epithelial mottling and retinal depigmentation and deposits are well described. ${ }^{12,13}$ Retinal involvement has been seen as early 3 years of age but is a constant feature from 7 years onwards. ${ }^{8}$ Reduced

a- and b-wave amplitudes on scotopic and photopic electroretinograms are described in some patients ${ }^{8,13}$ and may progress with age.

In this patient, the corneal crystals were initially deemed to be the cause of his visual problems. The cystine stores in non-renal tissues are said to be of little consequence until about the age of 10 years, ${ }^{12}$ but this child, although only 5 years of age, has severe visual loss due to retinopathy from cystine deposition. In the series published by Yamamoto et al., ${ }^{12}$ all 27 cases with nephropathic cystinosis had vision better than $6 / 12$. The age of the cases ranged from 2 to 19 years. There is no known therapy for the retinopathy and, despite renal transplant, retinopathy is known to progress. ${ }^{9,12}$ This case serves to remind us that patients with cystinosis and visual failure should be investigated for posterior segment involvement at all ages. It is particularly important to ascertain the cause of poor vision before embarking on corneal surgery.

\section{References}

1. Wong VG, Kuwabara T, Brubaker R, Olson W, Schulman J, Seegmiller JE. Intralysosomal cystine crystals in cystinosis. Invest Ophthalmol Vis Sci 1970;9:83-8.

2. Kenyon KR, Sensbenbrenner JA. Electron microscopy of cornea and conjunctiva in childhood cystinosis. Am J Ophthalmol 1974;78:68-76.

3. Gahl WA, Thoene JG, Schneider JA, O'Regan S, KaiserKupfer MI, Kuwabara T. Cystinosis: progress in a prototypic disease. Ann Intern Med 1988;109:557-69.

4. Wan WL, Minckler DS, Rao NA. Pupillary block glaucoma associated with childhood cystinosis. Am J Ophthalmol 1986;101:700-5.

5. Wong VG. Ocular manifestations in cystinosis. Birth Defects 1976;12:181-6.

6. Sanderson PO, Kuwabara T, Stark WJ, Wong VG, Collins EM. Cystinosis: a clinical, histopathological and ultrastructural study. Arch Ophthalmol 1974;91:270-4.

7. Melles RB, Schneider JA, Rao NA, Katz B. Spatial and temporal sequence of corneal crystal deposition in nephropathic cystinosis. Am J Ophthalmol 1987;104:598-604.

8. Dufier JL, Dhermy P, Gubler MC, Gagnadoux MF, Broyer M. Ocular changes in long term evolution of infantile cystinosis. Ophthalmic Paediatr Genet 1987;8:131-7.

9. Kaiser-Kupfer MI, Fujikawa L, Kuwabara T, Jain S, Gahl WA. Removal of corneal crystals by topical cysteamine in nephropathic cystinosis. N Engl J Med 1987;316:775-9.

10. Kaiser-Kupfer MI, Gazzo MA, Datiles MB, Caruso RC, Kuehl EM, Gahl WA. A randomised placebo-controlled trial of cysteamine drops in nephropathic cystinosis. Arch Ophthalmol 1990;108:689-93.

11. Kaiser-Kupfer MI, Datiles MB, Gahl WA. Clear graft two years after keratoplasty in nephropathic cystinosis. Am J Ophthalmol 1988;105:318-9.

12. Yamamoto GK, Schulman JD, Schneider JA, Wong VG. Long term ocular changes in cystinosis: observations in renal transplants recipients. J Paediatr Ophthalmol Strabismus 1979;16:21-5.
13. Richler M, Milot J, Quigley M, O'Regan S. Ocular manifestations of nephropathic cystinosis: The French Canadian experience in a genetically homogeneous population. Arch Ophthalmol 1991;109:359-62.

B.Y.P. Chang

N.D.L. George

Department of Ophthalmology

Leeds General Infirmary

Leeds, UK

Mr N.D.L. George, FRCOphth

Department of Ophthalmology

Leeds General Infirmary

Clarendon Wing

Belmont Grove

Leeds LS2 9NS, UK

Tel: $+44(0) 1133922627$

Fax: $+44(0) 1132926239$

\section{Sir,}

\section{The application of ultrasonic biomicroscopy in the management of traumatic hypotony}

Early diagnosis and prompt management of hypotony are important. We report a case of persistent hypotony after primary repair of scleral perforation. The management was guided by the ultrasonic biomicroscopy (UBM) findings.

\section{Case report}

A 13-year-old boy presented to another unit with a ruler injury resulting in a temporal scleral perforation, vitreous prolapse, vitreous haemorrhage and hyphaema. After a primary repair, he developed persistent hypotony and presented to our unit 1 month later. His best corrected visual acuity (VA) was $6 / 24$. The anterior segment findings included a mild relative afferent pupillary defect, a shallow anterior chamber (AC) associated with angle closure of the inferotemporal quadrant without any evidence of cyclodialysis on gonioscopy, a vitreous prolapse, a temporally subluxated lens, an intraocular pressure (IOP) of $4 \mathrm{mmHg}$ and mild posterior subcapsular lens opacification (Fig. 1a). The fundus showed a swollen optic disc, maculopathy and tortuous vessels (Fig. 1b). UBM imaging demonstrated $360^{\circ}$ of supraciliary effusion (Fig. 2a).

He underwent drainage of suprachoroidal fluid and resuturing of a ciliary body with $6 / 0$ polyglactin sutures through full-thickness sclerotomies (two per quadrant) 3 . $5 \mathrm{~mm}$ from the limbus. Sulphur hexafluoride $\left(\mathrm{SF}_{6}\right)$ gas $(20 \%)$ was injected into the AC as an internal tamponade. Post-operatively, the IOP was transiently maintained for 1 week only. He had a further operation 2 months later, which involved direct cyclopexy ${ }^{1}$ of two main supraciliary effusion areas (as demonstrated by UBM pre-operatively) and injection of $20 \% \mathrm{SF}_{6}$ gas into the $\mathrm{AC}$. A transient IOP rise was treated medically in the first 2 weeks post-operatively. He subsequently underwent anterior vitrectomy, phacoemulsification with a Morcher ring and silicone lens implantation 10 months after the original injury. His latest best corrected (VA) was 6/6 